\section{Objective evaluation of cataract progression associated with a high dose intravitreal triamcinolone injection}

YK Chu', EJ Chung², OW Kwon'², JH Lee ${ }^{3}$ and $\mathrm{HJ} \mathrm{Koh}{ }^{2}$

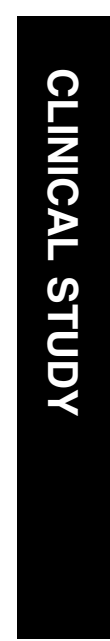

progression of cortical and posterior subcapsular opacity in patients with diabetic macular oedema and retinal vein occlusion. Eye (2008) 22, 895-899; doi:10.1038/sj.eye.6702802; published online 13 April 2007

Keywords: intravitreal triamcinolone acetonide; cataract; macular oedema

\section{Introduction}

The successful use of intravitreal triamcinolone acetonide (IVTA) to treat various macular oedema secondary to diabetic retinopathy, branch and central retinal vein occlusion, choroidal neovascularization, and, uveitis, etc. has lead to an increase in its usage during the past few years. ${ }^{1-7}$ However, the treatment with corticosteroids is generally associated with two common and serious ocular side effects: elevated intraocular pressure (IOP) and accelerated cataract formation. ${ }^{8-10}$

Studies involving IVTA exhibit a diverse range in the dosage of triamcinolone being injected. The reported effects of corticosteroid crystals resulted in decreased macular oedema and consequential improvement in vision. However, the vision improving effects have been reported to be temporary.,11 According to one prospective study, no significant improvement in visual acuity and no significant reduction in macular thickness could be observed 3 months after intravitreal injection of $4 \mathrm{mg}$ triamcinolone. ${ }^{12}$ This early disappearance of the effect of IVTA might be consistent with the results reported by Beer et al who calculated
${ }^{1}$ Siloam Eye Hospital, Seoul, Korea

${ }^{2}$ Department of Ophthalmology, The Institute of Vision Research, Yonsei University College of Medicine, Seoul, Korea

${ }^{3}$ Myung-Gok Eye Research Institute, Kim's Eye Hospital, Konyang University, Seoul, Korea

Correspondence: HJ Koh, Department of Ophthalmology, Yonsei University College of Medicine,

Sodaemungu Shinchondong 134, Seoul 120-752, Korea

Tel: + 8222228 3570; Fax: + 8223120541

E-mail: hjkoh@

yumc.yonsei.ac.kr

Received: 23 October 2006 Accepted in revised form: 13 February 2007 Published online: 13 April 2007

Proprietary or financial interest: none 
that measurable concentrations of triamcinolone could be expected to last no more than 3 months in nonvitrectomized eyes. ${ }^{13}$ On the other hand, the intravitreal injection of $25 \mathrm{mg}$ triamcinolone has been reported to have measurable concentration up to 6-8 months after the injection. ${ }^{14-17}$ We performed $25 \mathrm{mg}$ high dose intravitreal triamcinolone injection to circumvent the need for frequent repeated injections, which may predispose the patients to the higher rate of complications associated with the treatment.

The present study is to prospectively investigate the progression of cataract associated with the use of a high dose intravitreal triamcinolone injection with objective photographic evaluation and compared with a control group of noninjected fellow eyes in patients with macular oedema secondary to diabetes and retinal vein occlusion.

\section{Materials and methods}

This prospective interventional case series study included all 38 patients (27 women, 11 men; 76 eyes) who visited the Siloam Eye Hospital's retina clinic with diabetic retinopathy or retinal branch or central vein occlusion from the beginning of March to the end May 2005. The study followed the tenets of Declaration of Helsinki. Informed consent was obtained from every patient after explanation of the nature and possible consequences of the study.

The patients were included in the study if they had (1) macular oedema associated with diabetic retinopathy and branch or central retinal vein occlusion, documented by diffuse fluorescein leakage on angiography and thickening of retina on 90D noncontact lens slit lamp biomicroscopy; (2) best-corrected visual acuity $\leqslant 20 / 80$ measured with Snellen chart; and (3) phakic fellow eyes. The exclusion criteria were (1) pre-existing lens opacities obscuring fundus visualization; (2) intraocular surgery including cataract extraction; (3) prior history of elevated intraocular pressure responsive to steroid treatment;

(4) history of glaucoma or ocular hypertension; and

(5) presence of known conditions as uveitis, ocular trauma, prolonged use of topical or systemic corticosteroids that may contribute to cataract formation.

The IVTA injection was carried out as follows for all patients. The procedure was done under aseptic conditions in the operation room. A lid speculum was placed between the eyelids. The conjunctiva, eyelids, and eyelashes were disinfected with $10 \%$ povidone iodine. Topical $0.5 \%$ proparacaine hydrochloride drops (Alcaine ${ }^{\circledR}$; Alcon Laboratories, Fort Worth, TX, USA) were then placed on the ocular surface, followed by application of $4 \%$ topical lidocaine using a cotton tip pledget over the injection site. Triamcinolone acetonide (40 mg/ml; Bristol Myers Squibb Co., New York, NY,
USA) was drawn into a $1 \mathrm{~cm}^{3}$ syringe after first cleansing the top of the container with an alcohol wipe. The $1 \mathrm{~cm}^{3}$ syringe was then tape on to the wall needle side up for approximately $3 \mathrm{~h}$ before injection so that the white triamcinolone crystals precipitate to the bottom of the syringe. The clear supernatant was discarded leaving only $0.1 \mathrm{~cm}^{3}$ triamcinolone crystals. The remaining $0.05 \mathrm{~cm}^{3}$ was injected via 30 -gauge needle $4 \mathrm{~mm}$ from the limbus in the inferior temporal quadrant. The proper intravitreal localization of the suspension and the perfusion of the optic nerve head were then confirmed by indirect ophthalmoscopy.

Patients were asked to return the next day and weekly for 1 month and monthly thereafter for photographic evaluation of grading of lens opacification, visual acuity, fundus evaluations, and IOP exams. The slit lamp photography was taken using a digital camera (Nikon coolpix 5400) connected to a 900 Haag-Streit slit lamp biomicroscopy. Three sets of slit lamp photographs were taken for each patient. A slit lamp photograph was taken using reflected light with slit angle of $45^{\circ}$ to document the nuclear sclerosis and two retroillumination photographs to document the cortical and posterior subcapsular opacities. The photographs were taken by one experienced ophthalmic technician.

The main outcome measurement was the degree of cataract progression, which was measured as the difference in cataract grade between baseline and the end point (6 months after the injections) of the study. Cortical, nuclear and posterior subcapsular (PSC) forms of cataract were graded separately using photographic evaluation according to Lens Opacities Classification System III (LOCS III) standard photographs by the same surgeon (YKC). ${ }^{18}$ Noninjected phakic fellow eyes served as a control. The preoperative and the end point vision between the control and IVTA eyes were compared using independent samples $t$-test. The preoperative and the end point vision and IOP of the IVTA eyes were analyzed with paired $t$-test. The progression of the 3 forms of cataract was then evaluated among the eyes treated with intravitreal triamcinolone and the untreated fellow eyes using the Kaplan-Meier survival analysis and the log-rank test. $P$-values of less than 0.05 were considered significant.

\section{Results}

A total of 38 eyes of 38 patients ( 27 female and 11 male) received intravitreal injection of $25 \mathrm{mg}$ triamcinolone acetonide. The mean age of the patients was $65.8 \pm 6.7$ (mean $\pm \mathrm{SD}$ ) years. The majority of the patients either had a history of diabetic mellitus (8 patients, 21\%), hypertension (7 patients, $18 \%$ ), or both (20 patients, $53 \%$ ). However, there were three patients $(8 \%)$ without known medical histories of either of the two. The demographic 
data and preoperatively diagnosed retinopathy of the patients are shown in Table 1.

Table 2 shows the visual acuity of both eyes before IVTA and at the end point (6 months) of the study. The average visual acuity was significantly higher in the control eye both at baseline and endpoint (independent samples $t$-test, $P<0.001$ at both baseline and end point). The average visual acuity in the intravitreal triamcinolone acetonide injected eye showed minor but no significant improvement at the end of 6 months comparing with the baseline (paired $t$-test, $P=0.41$ ).

Among the 38 treated eyes, there was an increase of cataract degree by 1 grade at the end of 6 months in 10 patients. The types of progressed cataract were PSC in seven patients, cortical in six patients, and nuclear sclerosis in one patient (Table 3). Four patients had both an increase in grade of PSC and cortical opacities while six patients had showed a progression of only one type of cataract.

Of the 10 patients who developed a progression of cataract, three showed an improvement in vision while

Table 1 Demographic data and diagnosed retinopathy of the patients

\begin{tabular}{lc}
\hline Characteristics & Number $(\%)$ \\
\hline Mean age (years) \pm SD & $65.8 \pm 6.7$ \\
Sex (male: female) & $11(29): 27(71)$ \\
DME & $26(68)$ \\
BRVO & $10(26)$ \\
CRVO & $1(3)$ \\
DME \& CRVO & $1(3)$ \\
\hline
\end{tabular}

Abbreviations: BRVO, branch retinal vein occlusion; CRVO, central retinal vein occlusion; DME, diabetic macular oedema.

Table 2 Average baseline and end point vision

\begin{tabular}{lccc}
\hline & Control eye & IVTA eye & P-value $^{\mathrm{a}}$ \\
\hline $\begin{array}{c}\text { Average baseline } \\
\text { vision (mean } \pm \text { SD) }\end{array}$ & $0.38 \pm 0.17$ & $0.08 \pm 0.04$ & $<0.001$ \\
$\begin{array}{c}\text { Average end point } \\
\text { vision (mean } \pm \text { SD) }\end{array}$ & $0.37 \pm 0.17$ & $0.10 \pm 0.16$ & $<0.001$ \\
\begin{tabular}{c}
$P$-value $^{\mathrm{b}}$ \\
\hline
\end{tabular} & 0.49 & 0.41 & \\
\hline
\end{tabular}

aIVTA eye $v s$ control eye; independent samples $t$-test.

${ }^{\mathrm{b} B a s e l i n e} v s$ end-point vision within a group; paired $t$-test.

Table 3 Cataract progression by 1 or more grades over 6 months

\begin{tabular}{lclc}
\hline & NS $(\%)$ & CO $(\%)$ & PSCO $(\%)$ \\
\hline IVTA treated eyes $(n=38)$ & $1(3)$ & $6(16)$ & $7(18)$ \\
Control (fellow) eyes $(n=38)$ & $0(0)$ & $0(0)$ & $1(3)$ \\
\hline
\end{tabular}

Abbreviations: CO, cortical opacity; NS, nuclear sclerosis; PSCO, posterior subcapsular opacity. four sustained equal vision and three showed a decrease in vision at the end point (six months) of the study. Fluorescein angiographic exams of these 10 patients at the month 6 showed residual or recurred macular oedema in three patients all presenting a decrease in end point vision.

Figure 1 depicts the progression-free survival curves for PSC and cortical cataracts in the eyes treated with intravitreal injection of triamcinolone acetonide. There was a significantly higher rate of progression of PSC $(P=0.023, \log$-rank test $)$ and cortical opacities $(P=0.011)$ in the treated group while the progression of nuclear cataract was not significantly different between the treated eye and the control eye. The earliest cortical and PSC progression began 3 months after IVTA injection occurring in two patients. The other seven patients showed progression in the 4 and 5 th month and one patient progressed in the final month.

The average IOP was $14.01 \pm 2.90 \mathrm{mmHg}$ at baseline and $14.00 \pm 2.43,14.05 \pm 2.58$ and $13.79 \pm 2.34 \mathrm{mmHg}$ at 1 , 3 and 6 months postoperatively in the IVTA eye. The changes in IOP were not significant at any time points during follow-up period (paired $t$-test, $P=0.73,0.93$ and 0.34 at 1,3 and 6 months, respectively). One of the injected eyes (3\%) showed IOP elevation over $21 \mathrm{mmHg}$ at 3 months follow-up, that was controlled with topical antiglaucomatous medication.

\section{Discussion}

The injection of triamcinolone acetonide into the vitreous has many proven benefits of prompt resolution of macular oedema caused by various retinopathies and eventual improvement in vision. ${ }^{1-7}$ Although the exact mechanism of intravitreal triamcinolone acetonide in the treatment of macular oedema has not been well described, the possible mechanism may include local reduction of inflammatory mediators by the downregulation of vascular growth factors such as VEGF and anti-inflammatory effects through inhibition of the arachidonic acid pathway and prostaglandin (a known mediator of vascular permeability) production., ${ }^{79-22}$ Also, mechanisms of increased diffusion by the modulation of calcium channels, ${ }^{23}$ and improvement in blood-retinal barrier function ${ }^{24-26}$ may contribute to the healing effects of corticosteroids.

Despite the therapeutic effect for the macular oedema associated with various ocular pathologies, the intravitreal injection entails several complications and progression of the cataract is one of the most commonly reported. According to the study by Gillies et $a l^{27}$ significant progression of cataract was observed in triamcinolone-treated eyes. Cataract surgery was performed in $16(28.6 \%)$ of 56 treated eyes of patients who completed at least the 12-month study visit vs 2 

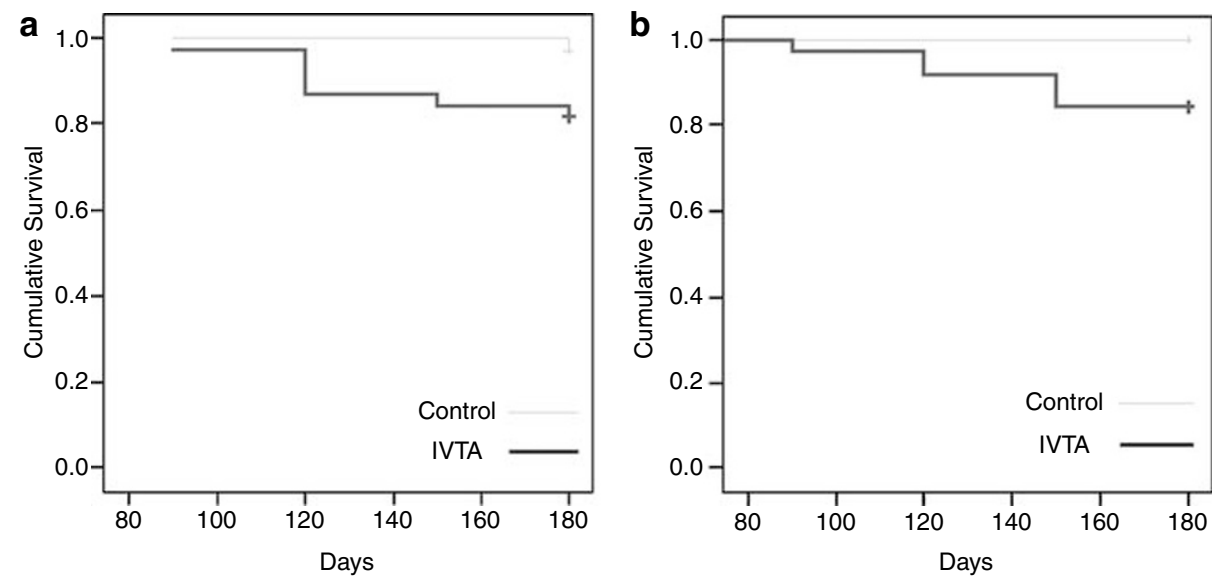

Figure 1 Progression-free survival curves for cataracts in the IVTA and control eyes. Time from treatment to progression by one or more grade is shown for (a) posterior subcapsular cataracts $(P=0.023, \log$-rank test), and (b) cortical cataracts $(P=0.011, \log$-rank test).

$(5.0 \%)$ of 40 eyes receiving placebo. Helm and Holland also reported development of significant cataract in four (36.4\%) of 11 phakic eyes 10 months to 4 years after treatment with triamcinolone injected into the posterior sub-Tenon space in the treatment of intermediate uveitis. ${ }^{28}$ The rate of cataract progression has reported previously to be variable from 0 to $23 \%$. $3,11,29-32$

The present study using a high dosage $(25 \mathrm{mg}$ ) of IVTA injection for a follow up of 6 months has revealed similar results; out of 38 patients enrolled into the analysis, 10 patients $(26.3 \%)$ eventually showed a progression of cataract. Among the three general types of cataract, not only PSC ( 7 eyes) but cortical opacities ( 6 eyes)

progressed under the influence of IVTA leaving nuclear sclerosis (one eye) to be the only type not significantly affected. Regarding the visual acuities, no significant difference in visual improvement 6 months following the IVTA injections were found. Among the 10 eyes that developed cataract progression, three eyes showed decrease in vision at the end point of the study but this was more so thought to be owing to the exacerbation of the macular oedema as documented on fluorescein angiographic examination rather than the progression of the cataract. The four patients among the 10 who showed resolved macular oedema but did not show an increase of vision may be because of the increase in cataract grade. If there is an improvement of macular oedema but not an improvement in vision after IVTA injections, the development or progression of cataract may be the reason.

The rate of cataract progression was comparable to those previously reported rate after $4 \mathrm{mg}$ intravitreal triamcinolone acetonide injection. The results suggest that the rate of cataract progression might not be increased by the higher dosage of triamcinolone within
6 months period. It is also consistent with the report by Lam $e t a l^{33}$ showing that the rate and degree of cataract progression was not different among the groups treated with different doses of intravitreal triamcinolone for diabetic macular oedema.

Some limitations are inherent in our study because of small sample size, and limited length of follow-up. Although the baseline cataract evaluations and all of the IVTA injections were carried out by a single surgeon, there may have been subjective variations in grading the degree of cataract according to Lens Opacities Classification System III (LOCS III) and in preparing the $25 \mathrm{mg}$ dosage of triamcinolone acetonide owing to the small volume handled. Scheimpflug type system using densitometric analysis might have been helpful in grading the nuclear sclerosis and quantitative analysis of the cataract progression. However, the Scheimpflug camera was not available at our institute and, practically, the system has limited value in clinical application due to the complicated handling of the camera, data analysis and cost comparing with the LOCS III system. ${ }^{34}$ Further studies in larger population group will be necessary to evaluate the long-term effects of high-dose intravitreal injection in cataract progression.

In this study, we could document the development and progression of the cataract after a high-dose IVTA using objective photographic evaluation according to LOCS III. Because the fellow eyes served as control group, we could circumvent the effect of variables within the patients that might have influenced on the progression of the cataract other than IVTA.

In conclusion, our results suggest that a high-dose $(25 \mathrm{mg}$ ) intravitreal triamcinolone acetonide injection is associated with progression of cortical and posterior subcapsular opacity in patients with diabetic macular 
oedema and retinal vein occlusion and might influence on vision improving effects of IVTA.

\section{References}

1 Jonas JB, Hayler JK, Sofker A, Panda-Jonas S. Intravitreal injection of crystalline cortisone as adjunctive treatment of proliferative diabetic retinopathy. Am J Ophthalmol 2001; 131: 468-471.

2 Jonas JB, Sofker A. Intraocular injection of crystalline cortisone as adjunctive treatment of diabetic macular edema. Am J Ophthalmol 2001; 132: 425-427.

3 Martidis A, Duker JS, Greenberg PB, Rogers AH, Puliafito $\mathrm{CA}$, Reichel $\mathrm{E}$ et al. Intravitreal triamcinolone for refractory diabetic macular edema. Ophthalmology 2002; 109: 920-927.

4 Antcliff RJ, Spalton DJ, Stanford MR, Graham EM, Ffytche TJ, Marshall J. Intravitreal triamcinolone for uveitic cystoid macular edema: an optical coherence tomography study. Ophthalmol 2001; 108: 765-772.

5 Young S, Larkin G, Branley M, Lightman S. Safety and efficacy of intravitreal triamcinolone for cystoid macular oedema in uveitis. Clin Exp Ophthalmol 2001; 29: 2-6.

6 Greenberg PB, Martidis A, Rogers AH, Duker JS, Reichel E. Intravitreal triamcinolone acetonide for macular oedema due to central retinal vein occlusion. Br J Ophthalmol 2002; 86: 248.

7 Yepremyan M, Wertz FD, Tivnan T, Eversman L, Marx JL. Early treatment of cystoid macular edema secondary to branch retinal vein occlusion with intravitreal triamcinolone acetonide. Opthalmic Surg Lasers Imaging 2005; 36: 30-36.

8 Wingate RJ, Beaumont PE. Intravitreal triamcinolone and elevated intraocular pressure. Aust N Z J Ophthalmol 1999; 27: 431-432.

9 Gillies MC, Kuzniarz M, Craig J, Ball M, Luo W, Simpson $\mathrm{JM}$ et al. Intravitreal triamcinolone-induced elevated intraocular pressure is associated with the development of posterior subcapsular cataract. Ophthalmology 2005; 112: 139-143.

10 Mohan R, Muralidharan AR. Steroid induced glaucoma and cataract. Indian J Ophthalmol 1989; 37: 13-16.

11 Massin P, Audren F, Haouchine B, Erginay A, Bergmann JF, Benosman $\mathrm{R}$ et al. Intravitreal triamcinolone acetonide for diabetic diffuse macular edema: preliminary results of a prospective controlled trial. Ophthalmology 2004; 111: 218-224.

12 Krepler K, Wagner J, Sacu S, Wedrich A. The effect of intravitreal triamcinolone on diabetic macular oedema. Graefes Arch Clin Exp Ophthalmol 2005; 243: 478-481.

13 Beer PM, Bakri SJ, Singh RJ, Liu W, Peters III GB, Miller M. Intraocular concentration and pharmacokinetics of triamcinolone acetonide after a single intravitreal injection. Ophthalmology 2003; 110: 681-686.

14 Kosobucki BR, Freeman WR, Cheng L. Photographic estimation of the duration of high dose intravitreal triamcinolone in the vitrectomized eye. $\mathrm{Br} \mathrm{J}$ Ophthalomol 2006; 90: 705-708.

15 Jonas JB. Concentration of intravitreally injected triamcinolone acetonide in intraocular silicone oil. $\mathrm{Br} \mathrm{J}$ Ophthalmol 2002; 86: 1450-1457.

16 Jonas JB. Concentration of intravitreally injected triamcinolone acetonide in aqueous humor. Br J Ophthalmol 2002; 86: 1066.
17 Jonas JB, Degenring R, Kamppeter B, Kreissig I, Akkoyun I. Duration of the effect of intravitreal triamcinolone acetonide as treatment of diffuse diabetic macular edema. Am J Ophthalmol 2004; 138: 158-160.

18 Chylack Jr LT, Wolfe JK, Singer DM, Leske MC, Bullimore MA, Bailey IL et al. The lens opacities classification system (LOCS) III: longitudinal study of the Cataract Study Group. Arch Ophthalmol 1993; 111: 831-836.

19 Kang BS, Chung EY, Yun YP, Lee MK, Lee YR, Lee KS et al. Inhibitory effects of anti-inflammatory drugs on interleukin-6 bioactivity. Biol Pharm Bull 2001; 24: 701-703.

20 Umland SP, Nahrebne DK, Razac S, Beavis A, Pennline KJ, Egan RW et al. The inhibitory effects of topically active glucocorticoids on IL-4, IL-5, and interferon-gamma production by cultured primary CD4 + T cells. J Allergy Clin Immunol 1997; 100: 511-519.

21 Floman N, Zor U. Mechanism of steroid action in ocular inflammation: inhibition of prostaglandin production. Invest Ophthalmol 1977; 16: 69-73.

22 Bandi N, Kompella UB. Budesonide reduces vascular endothelial growth factor secretion and expression in airway (Calu-1) and alveolar (A549) epithelial cells. Eur J Pharmacol 2001; 425: 109-116.

23 Sze PY, Iqbal Z. Glucocorticoid action on depolarizationdependent calcium influx in brain synaptosomes. Neuroendocrinology 1994; 59: 457-465.

24 Scholes GN, O’Brien WJ, Abrams GW, Kubicek MF. Clearance of triamcinolone from vitreous. Arch Ophthalmol 1985; 103: 1567-1569.

25 Schindler RH, Chandler DB, Thresher R, Machemer R. The clearance of intravitreal triamcinolone acetonide. Am J Ophthalmol 1982; 93: 415-417.

26 Wilson CA, Berkowitz BA, Sato Y, Ando N, Handa JT, de Juan Jr E et al. Treatment with intravitreal steroid reduces blood-retinal barrier breakdown due to retinal photocoagulation. Arch Ophthalmol 1992; 110: 1155-1159.

27 Gillies MC, Simpson JM, Billson FA, Luo W, Penfold P, Chua $\mathrm{W}$ et al. Safety of an intravitreal injection of triamcinolone: results from a randomized clinical trial. Arch Ophthalmol 2004; 122: 336-340.

28 Helm CJ, Holland GN. The effects of posterior subtenon injection of triamcinolone. Am J Ophthalmol 1995; 120: 55-64.

29 Challa JK, Gillies MC, Penfold PL, Gyory JF, Hunyor AB, Billson FA et al. Exudative macular degeneration and intravitreal triamcinolone: 18 month follow-up. Aust N Z J Ophthalmol 1998; 26: 277-281.

30 Chieh JJ, Roth DB, Liu M, Bellmont J, Nelson M, Reqillo C et al. Intravitreal triamcinolone acetonide for diabetic macular edema. Retina 2005; 25: 828-834.

31 Avitabile T, Longo A, Reibaldi A. Intravitreal triamcinolone compared with macular laser grid photocoagulation for the treatment of cystoid macular edema. Am J Ophthalmol 2005; 140: 695-702.

32 Jonas JB, Kreissing I, Sofker A, Degenring RF. Intravitreal injection of triamcinolone for diffuse diabetic macular edema. Arch Ophthalmol 2003; 121: 57-61.

33 Lam DS, Chan CK, Mohamed S, Lai TY, Li KK, Li PS et al. A prospective randomized trial of different doses of intravitreal triamcinolone for diabetic macular oedema. $\mathrm{Br} \mathrm{J}$ Ophthamol 2007; 91: 199-203.

34 Sasaki K. Cataract epidemiology performed with Scheimpflug documentation. Ophthalmic Res 1999; 31: 75-85. 